Hopfen (ziemlich viel, weil der Versuch sonst wohl zu winzig gewesen wäre) und Traubenzucker, worauf ausgepresst wurde. Beide Flüssigkeiten wurden getrennt behandelt. Die auszuschüttelnden Flüssigkeiten wurden etwas mit Weinsäure versetzt, da sie nicht sicher reagirten, dann mit Aether ausgeschüttelt.

In der That lieferte der Rückstand von der Verdunstung des Aethers mit Gerbstoff den gesuchten, in Essigsäure leichtlöslichen Niederschlag aus der zuerst abcolirten Hälfte des Malzauszuges, und die zweite, mit Leim etc. versetzte Hälfte lieferte die sämmtlichen Reactionen wie das untersuchte Bier, mit der einzigen Ausnahme, dass auch hier nicht der Dampf, sondern erst die flüssige Salpetersäure eine rothe Färbung erzeugte.

Ich halte mich demnach überzeugt, dass die von van Gelder und von mir beobachteten, anfangs auf Colchicin gedeuteten Reactionen aus Bier auf Bestandtheile des Malzes und des Hopfens zurückzuführen sind.

Am Schlusse dieser Mittheilungen kann ich nicht umhin, dem Herrn Wolff, Restaurateur auf hiesigem Bahnhofe, öffentlich meinen Dank zu sagen für die Liberalität, mit der er mir das zu untersuchende Bier gratis zur Verfügung stellte, nuchdem er von dem oben erwähnten Verdachte, in welchem Erlanger Bier stehen soll, gehört hatte. Es wäre zu wünschen, dass Alle, denen irgend welche Nahrungs - und Genussmittel in grösseren Mengen durch die Hand gehen, diesem Beispiele

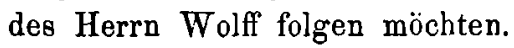

\title{
Zur Untersuchung des Bieres auf Stärkezucker.
}

Von Eugen Dieterich in Helfenberg.

Nachdem Béchamp die Entdeckung gemacht hatte, dass der künstliche Traubenzucker des Handels, der Kartoffelatärkezucker, eine nicht vergährungsfähige, stark rechts drehende Substanz, von ihm „Amylin" benannt, enthalte, gründete auf 
dies Verhalten F. A. Haarstick ${ }^{*}$ ) ein Untersuchungsverfahren, durch welches im Biere nachgewiesen werden konnte, ob beim Brauen desselben Kartoffelzucker verwendet worden war. H. liess $1 \mathrm{~L}$. Bier zur Syrupsconsistenz eindampfen, den Rückstand behufs Abscheidung des Dextrin's mit so viel Alkohol vermischen, bis eine abfiltrirte Probe mit absolutem Alkohol sich nicht mehr trübte, die über dem abgeschiedenen Dextrin stehende alkoholische Zuckerlösung nach 12 stündiger Ruhe abfiltriren, zum Trocknen eindampfen, den Rückstand in einem L. Wasser lösen, mit thierischer Kohle entfärben, filtriren und mit ausgewaschener Bierhefe bei $20^{\circ} \mathrm{C}$. gähren. Wenn am 2. oder 3. Tage frische Hefe zugeführt wurde, so war die Gährung am 4. beendet, und das Filtrat zeigte bei Bieren, welche ohne Kartoffelzucker bereitet waren, Null, im andern Falle eine mehr oder minder grosse Rechtsdrehung. Wenn nun zugestanden werden muss, dass die Béchamp'sche Beobachtung von $H$. geschickt verwerthet wurde, so war doch der Gang der Untersuchung ein so umständlicher und zeitrauhender, dabei in Bezug auf quantitative Bestimmung die Methode so ungeeignet, nachdem aller Zucker aus dem zäher gewordenen Dextrin in den Alkohol nicht übergeführt werden konnte, dass ich glaubte, nach dieser Richtung reformiren zu sollen und zwar durch Anwendung der Dialyse bei Trennung des Zuckers von Dextrin. Um mich zu vergewissern, dass Béchamp's "Amylin" auch ein Krystalloid sei, dialysirte ich käuflichen Stärkezucker, von dem ich bereits wusste, dass er nicht vollständig vergehè und "Amylin" hinterliess, und erzielte das für meine Absicht erfreuliche Resultat, dass eämmtlicher Zucker die Membran durchdrungen hatte. Eine andere Probe machte ich in der Weise, dass ich eine vergohrene Stärkezuckerlösung, die stark rechts drehte, also amylinhaltig war, ebenfalls dialysirte und auch hier den Rückstand im Dialysator bei der chemischen sowohl, wie bei der optischen Probe zuckerfrei und dem entgegen die Flüssig. keit ausserhalb des Dialysators zuckerhaltig fand. Es konnte

*) Chemisches Centralblatt 1876. S. 201. 
kein $\mathrm{Z}$ weifel mehr herrschen, dass die fragliche nach Neubauer's Ansicht zwischen Dextrin und Zucker stehende Substanz ein Krystalloid und dadurch ihre Verwandtschaft zum Zucker eine grössere sei, wie die zum Dextrin; ich möchte aber auch daraus folgern, dass die Béchamp'sche Bezeichnung "Amylin“ eine verfrühte und verfehlte ist. Nach dieser Abschweifung zu meinem Thema zurückkehrend hatte ich jetzt die Gewissheit, dass bei der Bier - Untersuchung der Zucker von Dextrin besser durch die Dialyse, wie nach Haarstick durch Alkohol getrennt werden könne; dass man ferner bei der Dialyse, wenn sie sorgfältig ausgeführt wird, sämmtlichen Zucker erhält.

Ich verfuhr nun in der Weise, dass ich 1 Liter Bier unter häufigem Erneuern des Wassers 4 Tage hindurch dialysirte, die Lösungen währendem und scbliesslich bis auf 1000 cc. eindampfte, mit thierischer Kohle entfärbte und filtrirte. Das Filtrat versetzte ich mit gewaschener Hefe, überliess es bei $20^{\circ} \mathrm{C}$. der Ruhe, so dass schon nach 2 Tagen keine Kohlensäure - Entwicklung mehr zu bemerken war. Der Sicherheit wegen setzte ich nochmals Hefe zu und wartete weitere 2 Tage, um dann zu filtriren und polarisiren. Das Resultat war das von Haarstick angegebene, wie ich durch Controlproben mich überzeugte; ich konnte aber auch auf Grund der Untersuchungen Neubauer's, ${ }^{*}$ ) wonach der Stärkezucker des Handels ca. $20 \%$ der besprochenen nicht vergährungsfähigen Substanz enthält, durch Eindampfen des letzten Filtrates die zum fraglichen Biere verbraute Quantität Stärkezucker annähernd bestimmen und rückschliessen, wie viel Malzschrot resp. Geld dadurch erspart worden sei, wenn ich, wie dies die Berichte der "Vierteljahresschrift zur Statistik des deutschen Reiches" thun, annahm, dass durch einen Centner Stärkezucker durchschnittlich $2 \frac{1}{2}$ Centner Malz ersetzt werden. Gerade diese Berechnungen dürten von Gewicht sein in streitigen Fällen, in welchen eine durch Anwendung von Surrogaten erzielte Uebervortheilung nachzuweisen ist.

*) Ber. der deutsch. chem. Gesellsch. VIII, 1285. 1875. 